Technological University Dublin

DƯBLIN

ARROW@TU Dublin

Articles

School of Biological Sciences

2007-08-01

\title{
PPAR $\boldsymbol{\alpha}$ is a Key regulator of Hepatic FGF21
}

Thomas Lundasen

Karolinska Institute, thomas.lundasen@ki.se

Mary Hunt

Technological University Dublin, mary.hunt@tudublin.ie

Lisa-Marie Nilsson

Karolinska Institute, lisa-marie.nilsson@ki.se

See next page for additional authors

Follow this and additional works at: https://arrow.tudublin.ie/scschbioart

Part of the Medicine and Health Sciences Commons

\section{Recommended Citation}

Lundåsen,L.,Hunt, M., Nilsson, L., Sanyal, S., Angelin, B., Alexon, S., Rudling, M. (2007) PPAR $\alpha$ is a key regulator of hepatic FGF21 Biochemical and Biophysical Research Communications, Volume 360, Issue 2, 24 August 2007, pp, 437-440. doi:10.1016/j.bbrc.2007.06.068

This Article is brought to you for free and open access by the School of Biological Sciences at ARROW@TU Dublin. It has been accepted for inclusion in Articles by an authorized administrator of ARROW@TU Dublin. For more information, please contact arrow.admin@tudublin.ie, aisling.coyne@tudublin.ie,gerard.connolly@tudublin.ie.

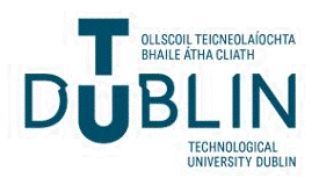




\section{Authors}

Thomas Lundasen, Mary Hunt, Lisa-Marie Nilsson, Sabysashi Sanyal, Bo Angelin, Stefan Alexson, and Mats Rudling 


\section{PPAR $\alpha$ is a key regulator of hepatic FGF21}

Thomas Lundåsen ${ }^{1,2}$, Mary C. Hunt ${ }^{3}$, Lisa-Marie Nilsson ${ }^{4}$, Sabysashi Sanyal ${ }^{2}$, Bo Angelin ${ }^{1,2}$,

Stefan E. H. Alexson ${ }^{3}$ and Mats Rudling ${ }^{1,2}$

Karolinska Institutet at ${ }^{1}$ Center for Endocrinology, Metabolism, and Diabetes, Department of Medicine, ${ }^{2}$ Department of Biosciences and Nutrition, NOVUM, and ${ }^{3}$ Department of Laboratory Medicine, Division of Clinical Chemistry, ${ }^{4}$ Division of Gastroenterology and Hepatology, Department of Medicine, Karolinska University Hospital, Huddinge, SE-141 86 Stockholm, Sweden

Running head: FGF21 is a PPAR $\alpha$ target gene.

\section{Correspondence:}

Mats Rudling, M.D., Ph.D. professor

Center for Endocrinology, Metabolism, and Diabetes

M63, Karolinska University Hospital, Huddinge

S-141 86 Stockholm, Sweden

$\mathrm{Ph}:+46-8-58586955$

Fax number: +46-8-7110710

Email: mats.rudling@,cnt.ki.se 


\begin{abstract}
The metabolic regulator fibroblast growth factor 21 (FGF21) has antidiabetic properties in animal models of diabetes and obesity. Using quantitative RT-PCR, we here show that the hepatic gene expression of FGF21 is regulated by the peroxisome proliferator-activated receptor alpha $(\operatorname{PPAR} \alpha)$. Fasting or treatment of mice with the PPAR $\alpha$ agonist Wy-14,643 induced FGF21 mRNA by 10-fold and 8-fold respectively. In contrast, FGF21 mRNA was low in PPAR $\alpha$ deficient mice, and fasting or treatment with Wy-14,643 did not induce FGF21. Obese ob/ob mice known to have increased PPAR $\alpha$ levels, displayed 12-fold increased hepatic FGF21 mRNA levels. The potential importance of PPAR $\alpha$ for FGF21 expression also in human liver was shown by Wy-14,643 induction of FGF21 mRNA in human primary hepatocytes and PPAR $\alpha$ response elements have been identified in both the human and mouse FGF21 promoters. Further studies on the mechanisms of regulation of FGF21 by PPAR $\alpha$ in humans is of great interest.
\end{abstract}

Key words: diabetes, fasting, fibrates, fibroblast growth factor 21, FGF21, ob/ob mice, peroxisome proliferator-activated receptor $\alpha, \operatorname{PPAR} \alpha, \mathrm{Wy}-14,643$ 


\section{Introduction}

The recently discovered metabolic regulator fibroblast growth factor 21 (FGF21), preferentially expressed in the liver [1], has been shown to exert strong antidiabetic and triglyceride-lowering effects and also to reduce body weight, when given to animals with dietinduced or genetic obesity and diabetes, but not when administered to normoglycemic animals [2-4]. In spite of these dramatic responses little is yet known about the mechanism of action of FGF21 or its regulation apart from a recently described synergistic effect with PPAR $\gamma$ in adipose tissue [5]. We recently found that the hepatic gene expression of FGF21 is induced 24 fold following pharmacological or genetic interruption of bile acid circulation, and that feeding a sucrose-rich diet induces hepatic FGF21 expression remarkably by 25 -fold [6] The highest FGF21 mRNA levels were seen in mice deficient in the apical sodium dependent transporter (ASBT) receiving a sucrose-rich diet. Interestingly, this diet also strongly reduced the high hepatic bile acid synthesis present in ASBT deficient animals, down to levels seen in normal wild type (wt) mice. Furthermore, the increase in hepatic triglycerides following the sucrose-rich diet in wt animals was attenuated in ASBT knock out mice [6].

The PPAR $\alpha$ is a nuclear receptor that has been shown to be a key transcriptional regulator of numerous genes involved in lipid metabolism ( for review see [7]). Targeted disruption of the PPAR $\alpha$ by Lee et al substantiated the role of this receptor in lipid homeostasis [8]. The PPAR $\alpha$ was shown to be involved in the adaptive response of mice to fasting, since fasted PPAR $\alpha$ null mice show enhanced lipid accumulation in liver, are hypoglycaemic and have an impaired ketone body formation [9, 10]. Since PPAR $\alpha$ stimulation also reduces bile acid synthesis $[11,12]$ and plasma triglycerides $[11,13,14]$ we speculated that PPAR $\alpha$ may be involved in the regulation of the expression of hepatic FGF21. To test this hypothesis we determined the FGF21 gene expression in liver from PPAR $\alpha$ deficient mice and wild-type 
controls during two different conditions known to stimulate PPAR $\alpha$ activity, i.e. treatment with the agonist Wy-14,643 and acute fasting. Our results show that the activation of a PPAR $\alpha$ response strongly induces the expression of FGF21 in normal mouse liver whereas in PPAR $\alpha$ deficient mice, having very low basal expression of FGF21, these responses were absent. In ob/ob mice that are known to have an increased PPAR $\alpha$ activity [15], hepatic basal FGF21 mRNA levels were increased 12-fold. Tentative PPAR $\alpha$ responsive elements (PPREs) were present in the promoter regions of both mouse and human FGF21 genes, and treatment of human primary hepatocytes with Wy-14,643 stimulated FGF21 mRNA expression. Our results suggest that FGF21 may be a direct transcriptional target of PPAR $\alpha$. 


\section{Material and methods}

Animals and treatment. Ten to twelve week old wild-type or PPAR $\alpha$-null male mice on a pure Sv/129 background (derived from the original colony of mixed background mice [8]) and male ob/ob mice obtained from Taconic, Ry, Denmark, were housed in a temperature and light-controlled environment. Mice were fed either a control chow diet (Lactamin R36, Vadstena, Sweden) or the chow diet containing 0.1\% w/w Wy-14,643 (Wyeth14,643, Calbiochem-Novabiochem International) for one week. In the fasting experiment, mice were fasted for 24 hours and sacrificed at $9.00 \mathrm{am}$. All mice had access to water ad libitum. Animals were sacrificed by $\mathrm{CO}_{2}$ asphyxiation, followed by cervical dislocation and livers were excised and snap frozen in liquid nitrogen and subsequently stored at $-70^{\circ} \mathrm{C}$. The studies were approved by the Institutional Animal Care and Use Committee.

Preparation of Total RNA from mouse liver and Quantitative Real Time PCR. Total RNA was prepared from mouse liver using Trizol or QuickPrep ${ }^{\circledR}$ Total RNA extraction kit and DNase treated using DNaseI (Promega). cDNA was synthesized from $1 \mu \mathrm{g}$ total RNA using SuperscriptIII according to the Manufacturer's instructions (Invitrogen). Quantitative Real time PCR was performed in the ABI 7500 FAST Real-Time PCR System and relative mRNA expression was calculated according to the Manufacturer's instructions (Applied Biosystems). TaqMan probes/primers were Assay on Demand; mouse FGF21 Assay ID: Mm00840165_g1, human FGF21 Assay ID: Hs00173927_m1. 18S and human acidic ribosomal phosphoprotein PO (RPLPO) were used as endogenous controls for mouse and human, respectively (Applied Biosystems).

Culture and Treatment of Human Primary Hepatocytes. Histologically normal liver tissue was obtained from a male subject following surgery for liver cancer at GastroCentrum, Karolinska University Hospital at Huddinge as part of studies approved by the Ethics 
Committee at the Karolinska Institutet. Hepatocytes were isolated by a two-step perfusion technique, utilizing EGTA and collagenase as described [16]. Cells were cultured in $60 \mathrm{~mm}$ Petri dishes coated with $200 \mu \mathrm{L}$ Engelbreth-Holm-Swarm (EHS) matrigel in $3 \mathrm{~mL}$ William's E medium with glutamax, supplemented with insulin (2 IU/L), penicillin (100 U/mL), streptomycin $(100 \mu \mathrm{g} / \mathrm{mL})$ and gentamycin $(85 \mu \mathrm{g} / \mathrm{mL})$. The medium was changed daily, and following four days in culture hepatocytes were incubated with $50 \mu \mathrm{M}$ Wy-14,643 or vehicle (dimethylsulfoxide, DMSO) for 48 hours. The medium was replaced with fresh medium containing $50 \mu \mathrm{M}$ Wy-14,643 after 24 hours. The hepatocytes were collected in Trizol and total RNA was isolated, treated with DNase1 (Promega Corp) and stored at $-70^{\circ} \mathrm{C}$. cDNA was synthesized as described above for mouse liver.

Statistics. The significance of differences between groups in Figures $1 \mathrm{~A}$ and B was tested by 1-way ANOVA followed by post-hoc comparisons according to Tukey using GraphPad Prism version 4.03 (GraphPad Software, San Diego California USA). For the experiments in Figure 2 and 4, statistical significance was tested by unpaired Student's $t$-test (GraphPad Software, SanDiego) 


\section{Results and Discussion}

We first evaluated whether the basal expression of liver FGF21 is reduced in animals devoid of PPAR $\alpha$ and whether there may be any differences between wt mice and mice devoid of PPAR $\alpha$ upon treatment with a selective PPAR $\alpha$ agonist (Figure 1A). FGF21 expression was strongly reduced in PPAR $\alpha$ deficient animals and treatment with Wy-14,643 was without effect in PPAR $\alpha$-null mice. This was in strong contrast to wt animals where there was a clear 8-fold increase in the expression of FGF21. Thus, in line with our hypothesis, the expression of FGF21 in this experiment appeared to be completely dependent on the presence of PPAR $\alpha$ indicating that FGF2 1 could be a target of PPAR $\alpha$. Based on the results obtained in this pharmacological model, we next explored if FGF21 could be influenced by PPAR $\alpha$ under more physiological conditions.

For this purpose, we studied the expression of hepatic FGF21 following 24 hours fasting. Previous experiments have shown that PPAR $\alpha$ deficient mice have a clearly reduced capacity to withstand food deprivation compared to wt mice that appears in part to be due to an impaired ability to form glucose and ketone bodies which is vital during prolonged fasting [9, 10]. We found that the FGF21 mRNA was strongly induced (10-fold) in livers of wt mice after 24 hours fasting, whereas in PPAR $\alpha$ deficient mice, again expressing very low basal levels of FGF21, there was no induction of FGF21 mRNA (Figure 1B). Therefore under physiological conditions that activate PPAR $\alpha$, FGF21 is induced, lending further support to the possibility that FGF21 is actually a target gene of PPAR $\alpha$.

Leptin deficient mice (ob/ob) are known to have activated PPAR $\alpha$ function, presumably due to increased levels of hepatic fatty acids [15]. We therefore hypothesized that ob/ob mice would have an increased hepatic expression of FGF21. mRNA levels of FGF21 were therefore measured in the livers of male ob/ob mice and indeed were shown to be elevated 12fold (Figure 2). 
The FGF21 gene is positioned on chromosome 7 and 19 in mouse and human, respectively. This region appears well conserved between the species and both the human and the mouse FGF21 genes are located in close proximity to the fucosyltransferase 1 (FUT1) gene. As shown in figure 3, we identified two putative PPREs in the mouse as well as human FGF21 promoter regions. These regions are located at -1143 and -2895 upstream of the translation start site (ATG) in the mouse gene and at -684 and -2454 in the human gene. Interestingly the direct repeat 1 (DR1) site located at -2895 in mouse is in fact a direct repeat 2 (DR2) in humans, with only 9 of the 13 base pairs conserved between species.

The finding of putative PPREs also in the human FGF21 gene prompted us to evaluate whether the increased gene expression of FGF21 elicited by Wy-14,643 treatment in mice may also occur in human hepatocytes. When human primary hepatocytes were treated with Wy-14,643, FGF21 gene expression was clearly induced 3-fold (Figure 4). Although these results indicate that PPAR $\alpha$ is important also for the hepatic expression of FGF21 in humans, further studies remain to be performed to further explore this regulation. It could be speculated that this lack of conservation between these sites in human and mouse could account for the weaker regulation evident by $\mathrm{Wy}-14,643$ in human hepatocytes compared to the regulation of FGF21 in mouse liver and could be due to interaction of other transcription factors on the same regulatory element. A DR2 flanked by an AT rich 5' region in the human Rev-erb $\alpha$ promoter was shown to bind the PPAR $\alpha /$ RXR heterodimer and was responsible for fibrate activation of the human Rev-erb $\alpha$ [17.]. Further experiments are therefore required to examine if these DR1 or DR2 elements can in fact mediate the PPAR $\alpha$ activation of the FGF21 genes in mouse or human.

Important questions to be answered are whether the gene expression of FGF21 is influenced by the feeding-fasting transition in humans, as recently reported for FGF19 [18]. It will be of particular interest to find out whether pharmacological treatment with PPAR $\alpha$ agonists such 
as fibrates may induce hepatic FGF21 expression and possible secretion of the protein into the blood in humans. Such mechanisms may explain some of the positive effects on triglyceride and glucose metabolism reported in response to fibrate therapy in humans [14]. Future studies are thus needed to establish whether pharmacological treatment with FGF21 protein in humans has similar metabolic effects to those previously shown in rodents and monkeys.

\section{Acknowledgements}

This work was supported by grants from the Swedish Research Council, the Swedish HeartLung Foundation, the Foundation of Old Female Servants, the Grönberg and the Novo Nordisk foundations, the Stockholm County Council (ALF) and the Karolinska Institutet. We thank Dr Frank J. Gonzalez and Dr Jeffrey M. Peters for the PPAR $\alpha$ knockout animals. 


\section{References}

[1] T. Nishimura, Y. Nakatake, M. Konishi, N. Itoh, Identification of a novel FGF, FGF-21, preferentially expressed in the liver, Biochim Biophys Acta 1492 (2000) 203-206.

[2] W. Wente, A.M. Efanov, M. Brenner, A. Kharitonenkov, A. Koster, G.E. Sandusky, S. Sewing, I. Treinies, H. Zitzer, J. Gromada, Fibroblast growth factor-21 improves pancreatic beta-cell function and survival by activation of extracellular signal-regulated kinase $1 / 2$ and Akt signaling pathways, Diabetes 55 (2006) 2470-2478.

[3] A. Kharitonenkov, V.J. Wroblewski, A. Koester, Y.F. Chen, C.K. Clutinger, X.T. Tigno, B.C. Hansen, A.B. Shanafelt, G.J. Etgen, The metabolic state of diabetic monkeys is regulated by fibroblast growth factor-21, Endocrinology 148 (2007) 774-781.

[4] A. Kharitonenkov, T.L. Shiyanova, A. Koester, A.M. Ford, R. Micanovic, E.J. Galbreath, G.E. Sandusky, L.J. Hammond, J.S. Moyers, R.A. Owens, J. Gromada, J.T. Brozinick, E.D. Hawkins, V.J. Wroblewski, D.S. Li, F. Mehrbod, S.R. Jaskunas, A.B. Shanafelt, FGF-21 as a novel metabolic regulator, J Clin Invest 115 (2005) 1627-1635.

[5] J.S. Moyers, T.L. Shiyanova, F. Mehrbod, J.D. Dunbar, T.W. Noblitt, K.A. Otto, A. Reifel-Miller, A. Kharitonenkov, Molecular determinants of FGF-21 activity-synergy and cross-talk with PPARgamma signaling, J Cell Physiol 210 (2007) 1-6.

[6] T. Lundasen, Studies on the hormonal regulation of bile acid synthesis $\mathrm{PhD}$ Thesis, Department of Medicine, Huddinge, Karolinska Institutet, Stockholm, 2007, 43.pages, ISBN: $978-91-7357-053-4$

[7] S. Mandard, M. Muller, S. Kersten, Peroxisome proliferator-activated receptor alpha target genes, Cell Mol Life Sci 61 (2004) 393-416.

[8] S.S. Lee, T. Pineau, J. Drago, E.J. Lee, J.W. Owens, D.L. Kroetz, P.M. FernandezSalguero, H. Westphal, F.J. Gonzalez, Targeted disruption of the alpha isoform of the 
peroxisome proliferator-activated receptor gene in mice results in abolishment of the pleiotropic effects of peroxisome proliferators, Mol Cell Biol 15 (1995) 3012-3022.

[9] T.C. Leone, C.J. Weinheimer, D.P. Kelly, A critical role for the peroxisome proliferatoractivated receptor alpha (PPARalpha) in the cellular fasting response: the PPARalpha-null mouse as a model of fatty acid oxidation disorders, Proc Natl Acad Sci U S A 96 (1999) 7473-7478.

[10] S. Kersten, J. Seydoux, J.M. Peters, F.J. Gonzalez, B. Desvergne, W. Wahli, Peroxisome proliferator-activated receptor alpha mediates the adaptive response to fasting, $\mathrm{J}$ Clin Invest 103 (1999) 1489-1498.

[11] D. Stahlberg, E. Reihner, M. Rudling, L. Berglund, K. Einarsson, B. Angelin, Influence of bezafibrate on hepatic cholesterol metabolism in gallstone patients: reduced activity of cholesterol 7 alpha-hydroxylase, Hepatology 21 (1995) 1025-1030.

[12] M. Marrapodi, J.Y. Chiang, Peroxisome proliferator-activated receptor alpha (PPARalpha) and agonist inhibit cholesterol 7alpha-hydroxylase gene (CYP7A1) transcription, J Lipid Res 41 (2000) 514-520.

[13] S. Fazio, M.F. Linton, The role of fibrates in managing hyperlipidemia: mechanisms of action and clinical efficacy, Curr Atheroscler Rep 6 (2004) 148-157.

[14] J.P. Despres, I. Lemieux, S.J. Robins, Role of fibric acid derivatives in the management of risk factors for coronary heart disease, Drugs 64 (2004) 2177-2198.

[15] R.A. Memon, L.H. Tecott, K. Nonogaki, A. Beigneux, A.H. Moser, C. Grunfeld, K.R. Feingold, Up-regulation of peroxisome proliferator-activated receptors (PPAR-alpha) and PPAR-gamma messenger ribonucleic acid expression in the liver in murine obesity: troglitazone induces expression of PPAR-gamma-responsive adipose tissue-specific genes in the liver of obese diabetic mice, Endocrinology 141 (2000) 4021-4031. 
[16] S.C. Strom, L.A. Pisarov, K. Dorko, M.T. Thompson, J.D. Schuetz, E.G. Schuetz, Use of human hepatocytes to study P450 gene induction, Methods Enzymol 272 (1996) 388-401.

[17] P. Gervois, S. Chopin-Delannoy, A. Fadel, G. Dubois, V. Kosykh, J.C. Fruchart, J.

Najib, V. Laudet, B. Staels, Fibrates increase human REV-ERBalpha expression in liver via a novel peroxisome proliferator-activated receptor response element, Mol Endocrinol 13 (1999) 400-409.

[18] T. Lundasen, C. Galman, B. Angelin, M. Rudling, Circulating intestinal fibroblast growth factor 19 has a pronounced diurnal variation and modulates hepatic bile acid synthesis in man, J Intern Med 260 (2006) 530-536. 


\section{Figure legends}

Figure 1. PPAR $\alpha$ regulates FGF21 in mouse liver.

A, Male wild type or PPAR $\alpha$-null mice were treated for one week with $0.1 \% \mathrm{Wy}-$ 14,643. mRNA levels of FGF21 were measured using real time PCR as described in Materials and Methods. mRNA expression is displayed as fold change where the expression of the wt group is normalized to 1. Data show mean $+/-$ SEM. $n=3$.

B, Mice were fasted for 24 hours and mRNA levels of FGF21 were measured using real time PCR as described in Materials and Methods. mRNA expression is displayed as fold change where the expression of the wt group is normalized to 1. Data show mean $+/-$ SEM. $n=3$.

Figure 2. Comparison of hepatic expression of FGF21 mRNA in ob/ob mice and lean controls. mRNA was measured in the livers of male ob/ob and lean mice. Hepatic mRNA expression is displayed as fold change where the expression of the lean group is normalized to 1 . Data show mean +/- SEM. $n=5-6$.

Figure 3. The promoter regions of mouse and human FGF21 genes contain putative peroxisome proliferator-response elements (PPREs). The mouse and human FGF21 promoter regions were aligned using ClustalW. Two putative peroxisome proliferator-response elements are shown in boldface and underlined. The numbering shown is the position upstream of the translation start site ATG.

Figure 4. FGF21 expression is increased in human primary hepatocytes by the PPAR $\alpha$ agonist Wy-14,643 (Wy). Human primary hepatocytes were treated with $50 \mu \mathrm{M}$ Wy-14,643 for 48 hours. mRNA expression is displayed as fold change where the expression of vehicle-treated cells is normalized to 1 . Data show mean +/- SEM. $\mathrm{n}=6$. 
Figure 1
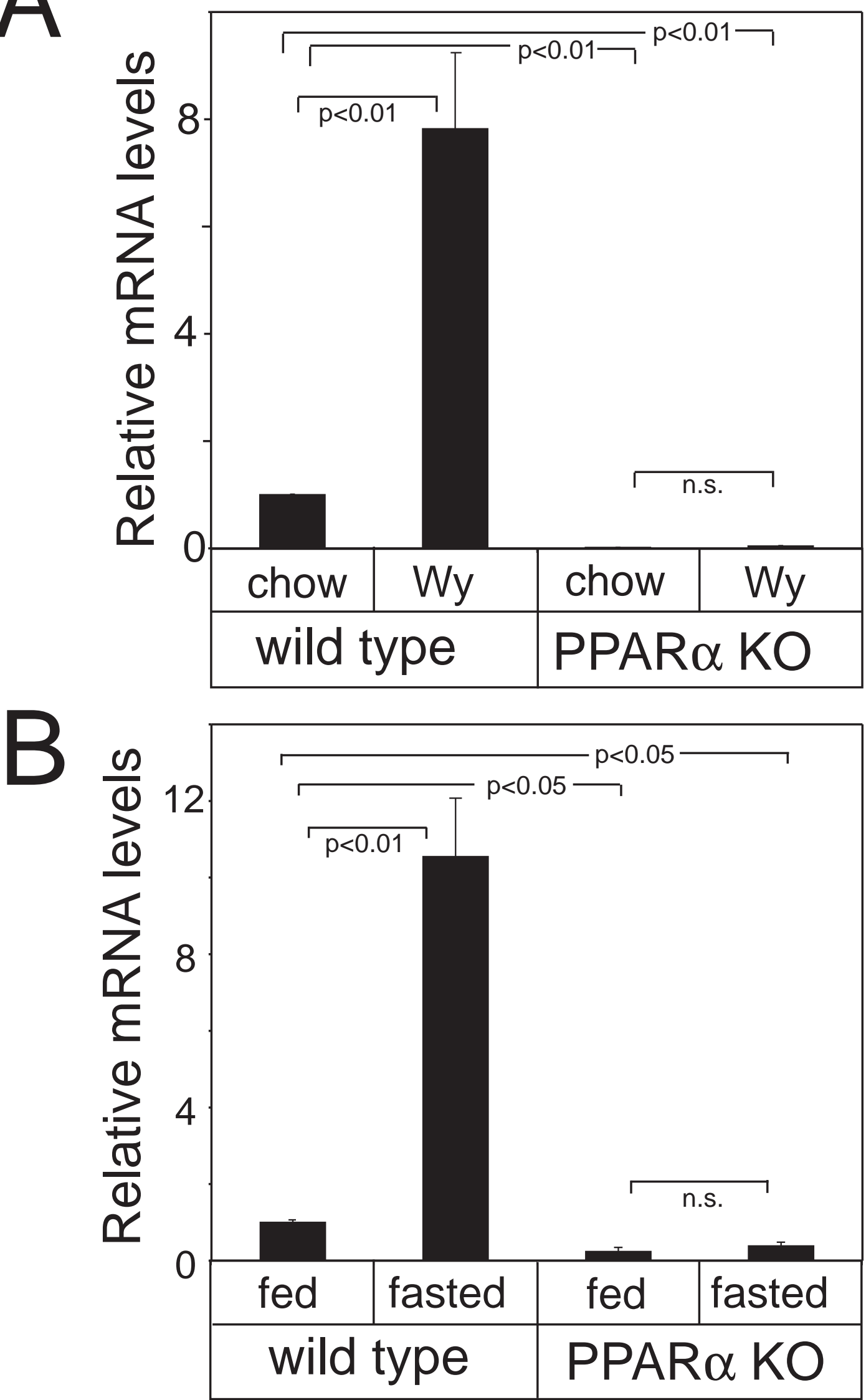
Figure 2

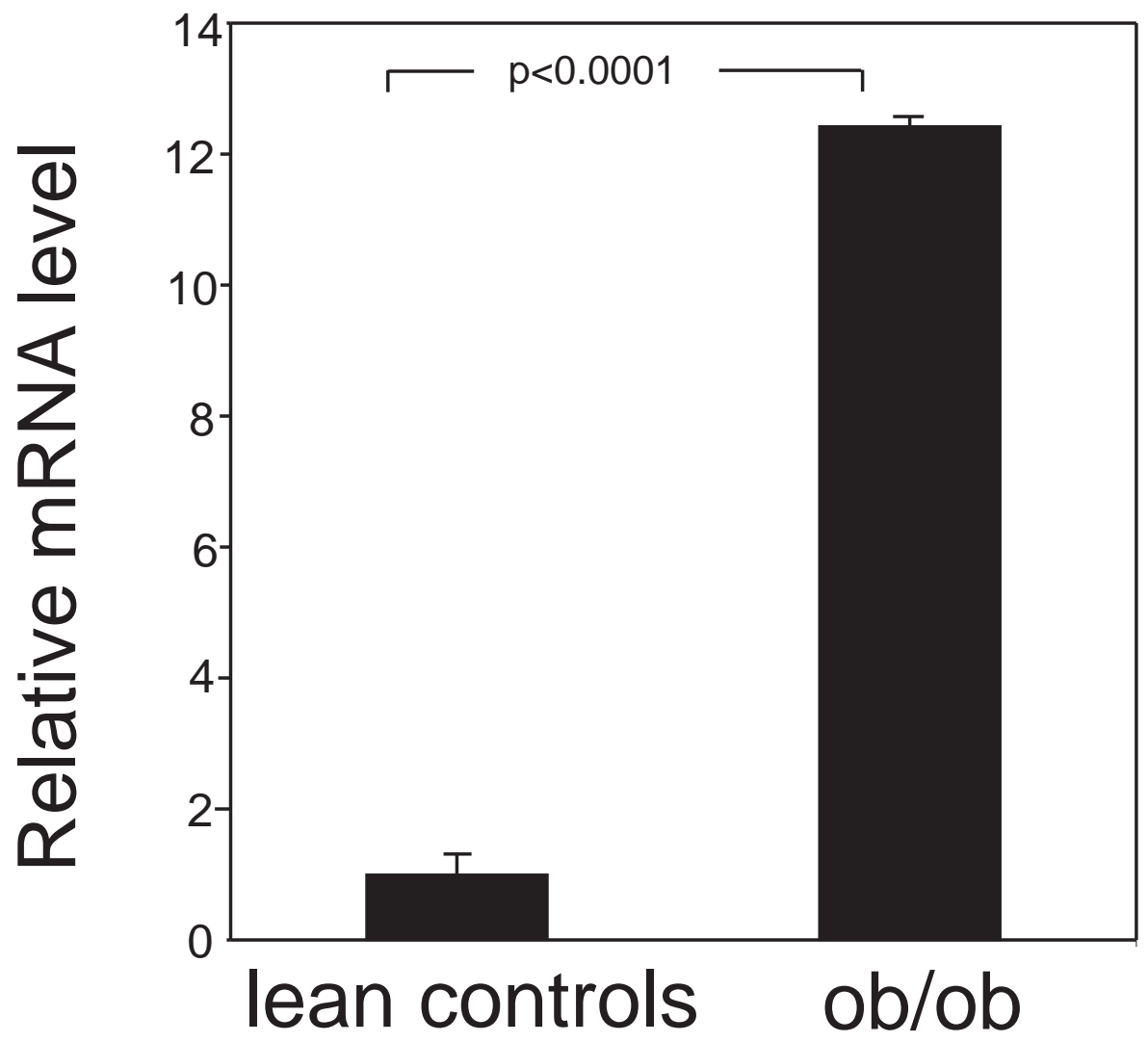


Figure 4

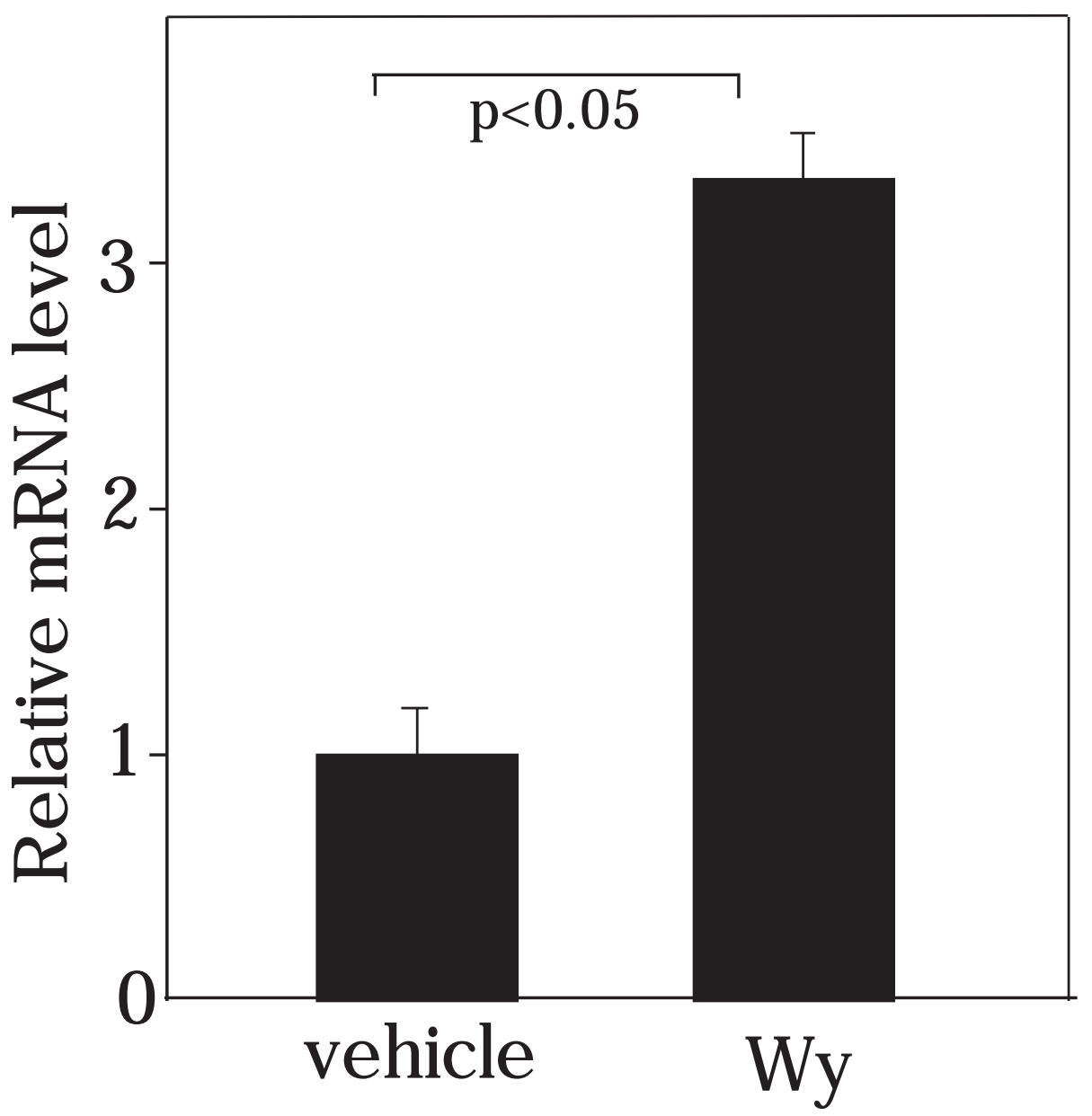

